D.O.I.: $10.3895 / \mathrm{S} 1808-04482008000100011$

\title{
DIRETRIZES GERAIS PARA A IMPLANTAÇÃO DE SISTEMAS DE GESTÃO DA SEGURANÇA E SAÚDE NO TRABALHO
}

\section{GUIDELINES FOR IMPLEMENTING OCCUPATIONAL HEALTH AND SAFETY SYSTEMS}

\author{
Alessandra Bizan de Oliveira ${ }^{1}$; Otávio José de Oliveira ${ }^{2}$ \\ ${ }^{1}$ Universidade Estadual Paulista - UNESP - Bauru - Brasil alebizan@terra.com.br \\ ${ }^{2}$ Universidade Estadual Paulista - UNESP - Bauru - Brasil otavio@,feb.unesp.br
}

\begin{abstract}
Resumo
Atualmente as organizações têm enfrentado constantes desafios relacionados à tecnologia $e$ qualidade de processos e produtos, desenvolvimento sustentável, posicionamento estratégico, motivação e bem estar de seus colaboradores. Neste contexto, os Sistemas de Gestão da Segurança e Saúde no Trabalho ganham, juntamente com os Sistemas de Gestão de Qualidade e Meio Ambiente, um significado cada vez mais importante nos resultados das empresas, reduzindo os riscos de acidentes, promovendo a saúde e a satisfação dos trabalhadores e melhorando a imagem da organização perante a sociedade. No entanto, para que um Sistema de Gestão da Segurança e Saúde no Trabalho seja efetivamente implementado e obtenha bons resultados, as empresas precisam estar mais atentas aos problemas e as dificuldades encontradas durante este processo, procurando solucioná-los de uma maneira eficaz e coerente com seus objetivos Pelo exposto, este artigo tem como principal objetivo formular diretrizes gerais e introdutórias para a implantação de Sistemas de Gestão da Segurança e Saúde no Trabalho, elaboradas a partir de uma revisão teórica. Um estudo-de-caso também foi realizado em uma empresa fabricante de baterias automotivas, localizada na região de Bauru, porém ele aqui tem apenas função exploratória, pois sabemos que não se devem fazer generalizações a partir dele.
\end{abstract}

Palavras-chave: sistemas de gestão; segurança e saúde do trabalho; OHSAS 18001.

\section{Introdução}

O cenário extremamente competitivo tem imputado às organizações a necessidade de modernização de seus processos e a incessante procura por novas ferramentas que possam trazer reais vantagens competitivas. Neste contexto, os Sistemas de Gestão da Segurança e Saúde surgem como ferramentas cada vez mais importantes para a melhoria do desempenho financeiro, operacional e social das organizações.

Primeiro, porque o bom desempenho em segurança e saúde no trabalho é decisivo para a rentabilidade da empresa, uma vez que reduz os riscos de acidentes; promove a saúde e a satisfação 
dos trabalhadores; melhora os resultados operacionais e a imagem da organização perante a sociedade, além de criar novas oportunidades de crescimento. Segundo, porque o crescente nível de conscientização e organização da sociedade tem imputado a estas organizações requisitos legais cada vez mais rigorosos.

Estudos mostram que a preocupação das empresas com a segurança e saúde no trabalho vem crescendo nos últimos anos, e muitas delas citam a redução do número de acidentes e doenças ocupacionais como um de seus maiores desafios (BROWN, 1996).

Segundo Quelhas, Alves e Filardo (2003), a melhoria na segurança e saúde no trabalho, além de aumentar a produtividade, reduz o custo do produto final, pois diminui as interrupções no processo, o absenteísmo e os acidentes e doenças ocupacionais.

Além do custo humano, acidentes e doenças do trabalho impõem prejuízos financeiros aos indivíduos, aos empregadores e à sociedade como um todo.

Durante o processo de implantação de Sistemas de Gestão da Segurança e Saúde no Trabalho, as organizações se deparam com diversos problemas e dificuldades, os quais causam transtornos tanto para a direção quanto para os demais colaboradores.

Pelo exposto, este artigo tem como principal objetivo formular diretrizes gerais e introdutórias para a implantação de Sistemas de Gestão da Segurança e Saúde no Trabalho, elaboradas a partir de uma revisão teórica. Um estudo-de-caso com foco neste tema foi realizado em uma empresa fabricante de baterias automotivas, localizada na região de Bauru, porém ele aqui tem apenas função exploratória, pois sabemos que não se devem fazer generalizações a partir dele. Os instrumentos de coleta de dados utilizados para sua realização foram entrevistas semi-estruturadas, realizadas a partir de questões abertas dirigidas ao técnico de segurança da empresa, observação in loco e análise de documentos, principalmente os procedimentos e instruções de trabalho.

\section{Sistemas de gestão da segurança e saúde no trabalho}

O processo de implantação de um sistema de gestão agrega valor à cultura organizacional, pois desenvolve competências relacionadas com o planejamento e execução das atividades, prioriza a capacidade de trabalho em equipe e promove a melhoria da confiabilidade dos sistemas produtivos.

Arantes (apud SILVA et al., 2004) define o sistema de gestão como um conjunto de instrumentos que a administração utiliza para facilitar a realização de suas tarefas. Ele auxilia nos esforços para definir procedimentos e métodos para execução das atividades, a compartilhar os papéis e as responsabilidades entre a equipe e promover as relações e o entendimento comum. 
O sucesso de um bom sistema de gestão consiste em obter eficiência e eficácia simultânea na utilização dos recursos organizacionais.

Segundo a BSI-OHSAS 18001 - Occupational Health and Safety Assessment Series (1999), segurança e saúde no trabalho são as condições e os fatores que afetam o bem-estar de funcionários, trabalhadores temporários, pessoal contratado, visitantes e qualquer outra pessoa no local de trabalho. A submissão dos trabalhadores a condições impróprias de trabalho, além de ser um grande fator de risco a acidentes, pode reduzir a capacidade produtiva de uma organização, por isso sua adequada gestão tem se mostrado um importante fator para o aumento da produtividade e competitividade das empresas.

Um Sistema de Gestão da Segurança e Saúde no Trabalho pode ser definido como parte do sistema de gestão global que facilita o gerenciamento dos riscos de segurança e saúde no trabalho associados aos negócios da organização. Isto inclui a estrutura organizacional, atividades de planejamento, responsabilidades, práticas, procedimentos, processos e recursos para desenvolver, implementar, atingir, analisar criticamente e manter uma política de segurança e saúde no trabalho (BSI-OHSAS 18001, 1999).

Para Trivelato (2002), a implantação de sistemas de gestão da segurança e saúde no trabalho tem sido a principal estratégia para atacar o sério problema social e econômico dos acidentes e doenças relacionadas ao trabalho, e ainda pode ser usado pelas empresas como um fator para o aumento de sua competitividade. Barbosa Filho (2001) salienta que quando um funcionário é admitido em uma empresa, a percepção que ele tiver do ambiente físico e social encontrado o influenciará em como se comportar no cotidiano. Por isso, são de suma importância aspectos como ordem, limpeza e asseio pessoal, bem como a própria organização e utilização dos espaços por meio de um layout adequado.

\section{Sistema de gestão da segurança e saúde no trabalho BSI-OSAS 18001}

Em 1999 foi publicada pela British Standards Instituion (BSI) a norma BSI-OHSAS 18001 (Occupational Health and Safety Assessment Series), que foi formulada por um grupo de entidades internacionais (BVQI, DNV, LOYDS, SGS e outras) que tomaram como base à norma BS 8800 (British Standard).

A norma BSI-OHSAS 18001 tem como objetivo fornecer às organizações os elementos para construção de um Sistema de Gestão da Segurança e Saúde no Trabalho eficaz, aplicável a todos os tipos e portes de empresas e passível de integração com outros sistemas de gestão (qualidade, meio ambiente e responsabilidade social), de forma a auxiliá-las a alcançar seus objetivos de segurança e 
saúde ocupacional. A BSI-OHSAS 18001 é aplicável a qualquer tipo de organização que tenha como objetivo (BSI-OHSAS 18001, 1999):

- Estabelecer um sistema de gestão da segurança e saúde no trabalho para minimizar os riscos aos empregados e outras partes interessadas;

- Implementar, manter e melhorar continuamente o seu sistema de gestão de segurança e saúde no trabalho;

- Assegurar-se de sua conformidade com a política de segurança e saúde no trabalho;

- Demonstrar sua conformidade a terceiros;

- Buscar a certificação de seu sistema de gestão por uma organização externa; e

- Realizar uma auto-avaliação de conformidade com a norma OHSAS.

Os requisitos da BSI-OHSAS 18001 são apresentados no Quadro 1.

Quadro 1: Requisitos da BSI-OHSAS 18001

\begin{tabular}{c|l}
\hline & \multicolumn{1}{|c}{ Requisitos } \\
\hline 4.1 & Requisitos gerais \\
\hline 4.2 & Política de segurança e saúde no trabalho \\
\hline 4.3 & Planejamento \\
\hline 4.3 .1 & Planejamento para identificação de perigos, avaliação e controle de riscos \\
\hline 4.3 .2 & Exigências legais e outras \\
\hline 4.3 .3 & Objetivos \\
\hline 4.3 .4 & Programa de gestão de segurança e saúde no trabalho \\
\hline 4.4 & Implementação e operação \\
\hline 4.4 .1 & Estrutura e responsabilidade \\
\hline 4.4 .2 & Treinamento, conscientização e competência \\
\hline 4.4 .3 & Consulta e comunicação \\
\hline 4.4 .4 & Documentação \\
\hline 4.4 .5 & Controle de documentos e dados \\
\hline 4.4 .6 & Controle operacional \\
\hline 4.4 .7 & Preparação e atendimento às emergências \\
\hline 4.5 & Verificação e ação corretiva \\
\hline 4.5 .1 & Medição e monitoramento do desempenho \\
\hline 4.5 .2 & Acidentes. Incidentes, não-conformidades e ações preventivas e corretivas \\
\hline 4.5 .3 & Registros e gestão de registros \\
\hline 4.5 .4 & Auditoria \\
4.6 & Análise crítica pela administração \\
\hline
\end{tabular}

Fonte: BSI-OHSAS 18001 (1999).

O princípio básico de um sistema de segurança no trabalho baseado em aspectos normativos envolve a necessidade de se determinar parâmetros de avaliação que incorporem não só os aspectos operacionais, mas também a política, o gerenciamento e o comprometimento da alta direção com o 
processo, como também a mudança e a melhoria contínua das condições de segurança e saúde no trabalho (QUELHAS, ALVES e FILARDO, 2003).

\section{Dificuldades encontradas na implantação de sistemas de gestão da segurança e saúde no trabalho}

A compreensão de que a gestão da segurança é uma atividade coletiva e deve ser exercida e realizada por todos é o primeiro passo para que a implementação desse projeto alcance o sucesso esperado; possibilitando, a partir disso, um entendimento comum que causa sinergia orientada para a segurança entre os colaboradores.

Ao longo da década de 80, o conceito de cultura organizacional ganhou grande destaque entre pesquisadores e executivos. Nessa época, anunciava-se que a chave para o sucesso das organizações era o desenvolvimento de uma cultura corporativa forte e única; e que a alta direção deveria construí-la por meio da articulação de um conjunto de valores, que seriam reforçados por políticas formais e informais e partilhada e respeitada por todos os colaboradores (MILAN, 2005). Assim sendo, a cultura corporativa tornou-se rapidamente uma arma a favor dos negócios bemsucedidos, sendo que atualmente, muitas organizações têm mostrado um interesse crescente no conceito da cultura de segurança como um meio de reduzir os riscos de desastres, acidentes e incidentes.

Estudos mostram que o sucesso na implantação de um sistema de segurança e saúde em uma organização depende da habilidade dos agentes responsáveis pelas mudanças em controlar situações complexas e imprevisíveis (HASLE e JENSEN, 2006).

Beer e Nohria (2001) salientam que a maioria dos casos de insucesso está na pressa de mudar a empresa. Os gestores confundem-se em suas iniciativas e perdem o foco com a quantidade de alternativas disponíveis na literatura e/ou propostas de consultores.

A eficiência destes sistemas poderia ser consideravelmente maior se fossem previamente observados alguns fatores negativos e de comum ocorrência, tais como: perfil e falta de experiência dos empresários nestes assuntos, indicadores de desempenho focados apenas nos aspectos financeiros, falta de constância de propósito, alegação de falta de tempo para realizar algumas tarefas de implantação, dificuldade de estabelecer metas e planos estratégicos a longo prazo, falta de visão dos funcionários como efetivos colaboradores para o crescimento da empresa, documentos mais burocráticos do que o necessário, alta rotatividade da força de trabalho e pouca utilização de alguns registros (ANHALON, ZOQUI e PINTO, 2005).

Maimon (apud CAGNIN, 2000) define de forma sumária quais as principais dificuldades na implantação de sistemas de gestão, conforme pode ser visto no Quadro 2. 
Quadro 2 - Principais obstáculos na implantação de sistemas de gestão

\begin{tabular}{|c|}
\hline BARREIRAS ORGANIZACIONAIS \\
\hline $\begin{array}{l}\text { - Enfase na sobrevivência - aspecto onde as empresas ficam vulneráveis ao fluxo de caixa; } \\
\text { - } \quad \text { Centralização das decisões; } \\
\text { - } \quad \text { Alta rotatividade da equipe técnica; e } \\
\text { - Falta de envolvimento dos empregados da empresa. }\end{array}$ \\
\hline BARREIRAS SISTÊMICAS \\
\hline $\begin{array}{ll}\text { - } & \text { Falta de informações relativas a legislação; } \\
\text { - } & \text { Sistema de gestão inadequado, funcionando sem planejamento e prioridades; e } \\
\text { - } & \text { Falta de capacitação técnica adequada dos funcionários. }\end{array}$ \\
\hline BARREIRAS COMPORTAMENTAIS \\
\hline $\begin{array}{l}\text { - } \quad \text { Resistência às mudanças; } \\
\text { - } \quad \text { Falta de lideranças; } \\
\text { - } \quad \text { Ausência de uma efetiva supervisão; e } \\
\text { - }\end{array}$ \\
\hline BARREIRAS TÉCNICAS E ECONÔMICAS \\
\hline $\begin{array}{l}\text { - } \quad \text { Falta de infra-estrutura; } \\
\text { - } \quad \text { Treinamento limitado ou não disponível; } \\
\text { - } \text { Acesso limitado às informações técnicas; } \\
\text { - Indisponibilidade de recursos e alto custo de financiamento; e } \\
\text { - Imprecisão dos custos na tomada de decisões e nas análises custo/ benefício. }\end{array}$ \\
\hline
\end{tabular}

Fonte: Adaptado de Cagnin (2000).

A aceitação e o entendimento do conceito da segurança e saúde por parte da Diretoria e a participação da área de recursos humanos neste processo de mudança é de fundamental importância para o que se consiga o envolvimento de todos os colaboradores e a obtenção de bons resultados.

O comprometimento da Alta Direção e a participação dos empregados na criação de uma cultura de segurança faz com que estes se sintam mais responsáveis quanto à prevenção e manutenção de um ambiente livre de acidentes e riscos a saúde (CHOUDHRY et al., 2006).

A compreensão de que a gestão da segurança é uma atividade coletiva e que deve ser exercida e realizada por todos é o primeiro passo para que a implementação deste sistema de gestão alcance o sucesso esperado; gerando, a partir disso, uma linguagem comum, que gera sinergia entre os colaboradores da organização em torno de uma mentalidade orientada para a segurança.

\section{Estudo-de-Caso}

Para esta pesquisa foi realizado um estudo-de-caso com função exploratória, que teve como objetivo dar maior embasamento aos pesquisadores e contribuir com a teoria apresentada. A empresa estudada é fabricante de baterias automotivas, está localizada na região centro-oeste do 
Estado de São Paulo e é certificada segundo as normas ISO 9001 (Sistema de Gestão da Qualidade) e ISO 14001 (Sistema de Gestão Ambiental), estando em processo de implantação da TS 16949 (Especificação automotiva) e OHSAS 18001 (Sistema de Gestão da Segurança e Saúde no Trabalho).

Atualmente o seu Sistema de Gestão da Segurança e Saúde no Trabalho se baseia em normas regulamentadoras instituídas pelo Ministério do Trabalho Brasileiro e nos demais requisitos aplicados ao setor de manufatura de baterias automotivas.

A Direção está consciente da importância da gestão da segurança e saúde na empresa e vem constantemente investindo na adequação do ambiente às condições seguras de trabalho.

A organização possui um Departamento de Segurança e Saúde no Trabalho composto por três técnicos de segurança, sendo todos eles subordinados a Diretoria Geral da organização.

A empresa possui implementado um Programa de Prevenção de Riscos Ambientais - PPRA, que tem como finalidade à preservação da saúde e integridade física dos trabalhadores. Os principais riscos gerenciados são: os químicos, proveniente da liberação de poeira e fumaça de chumbo, ácido sulfúrico, soda cáustica e vapores ácidos, os físicos, tais como ruídos, temperaturas extremas, eletricidade e alta pressão, e os ergonômicos, como carregamento excessivo de peso e postura inadequada.

O mapa de risco da empresa é elaborado pelos representantes da Comissão Interna de Prevenção de Acidentes (CIPA) sob a supervisão dos técnicos em segurança no trabalho e tem como objetivo fazer um levantamento das áreas de risco e sua gravidade para as atividades desenvolvidas. Para que os funcionários não sofram danos, a empresa possui em suas instalações Equipamentos de Proteção Coletiva (EPC's), e exige que seus colaboradores usem Equipamentos de Proteção Individual (EPI's) em áreas onde as atividades executadas geram riscos a sua segurança e saúde.

É realizado semanalmente um Diálogo Semanal de Segurança (DDS), onde são relatados aos trabalhadores os acidentes ocorridos na semana e as ações corretivas tomadas pela empresa para evitar a sua recorrência. Neste DSS, além de difundir informações relativas à segurança, a empresa também procura estimular a participação dos trabalhadores na sugestão de melhorias para a prevenção de acidentes.

Vale destacar que em um levantamento realizado pela empresa no ano de 2006, em torno de $44 \%$ dos acidentes ocorridos foram gerados por colaboradores contratados a menos de um ano.

Em função disto, a organização mantém um programa de integração com os novos funcionários, onde são dadas orientações sobre medidas de prevenção de acidentes e doenças ocupacionais. Este novo colaborador é acompanhado durante os primeiros seis meses de trabalho com maior rigidez que a média, onde é avaliado seu comportamento em relação às normas internas 
de segurança da empresa, e, caso seja necessário, intervenções são feitas pelos técnicos de segurança no trabalho.

Uma das grandes reclamações dos técnicos de segurança da empresa é o não atendimento por parte de alguns colaboradores das regras de segurança adotadas. Esta resistência, na maioria das vezes, tem início na média gerência, o que acaba gerando conflitos com os demais colaboradores, que também não se acham obrigados a as seguirem.

A maioria dos gerentes de nível médio que apresentam resistências às mudanças são antigos funcionários da empresa, que durante vários anos se mantiveram alheios às exigências do mercado e da sociedade; e, em muitos casos, esta deficiência acabou sendo causada pela própria empresa, devido à falta de incentivos para a busca de novos desafios e conhecimentos.

O trabalho dos responsáveis pela segurança é desenvolvido com cada colaborador, de acordo com seu nível de aceitação das normas e dos procedimentos relativos a segurança, procurando sempre desenvolver um programa personalizado para incutir a cultura de segurança nos mais resistentes.

A área de recursos humanos está iniciando um programa de desenvolvimento de lideranças, onde, além da média gerência, outros colaboradores serão treinados para entender e desenvolver trabalhos voltados à visão estratégica da organização, sendo a melhoria do sistema da segurança e saúde um dos principais objetivos.

Os resultados da segurança e saúde no trabalho na organização não estão vinculados a nenhum sistema de remuneração ou qualquer outro incentivo, porém existem estudos para que isto venha a acontecer no futuro.

De um modo geral, observa-se o investimento em melhorias na segurança e saúde, por meio do apoio dos técnicos de segurança no desempenho de suas funções e da busca de um maior envolvimento da área de recursos humanos neste processo.

Com as respostas obtidas por meio de entrevistas realizadas com o técnico de segurança, análise de documentos e observação in loco, foi possível fazer um levantamento das principais dificuldades enfrentadas pela empresa durante o período de implantação do Sistema de Gestão da Segurança e Saúde no Trabalho. Ver Quadro 3. 
Quadro 3 - Principais dificuldades encontradas na implantação do Sistema de Gestão da Segurança e Saúde no

Trabalho

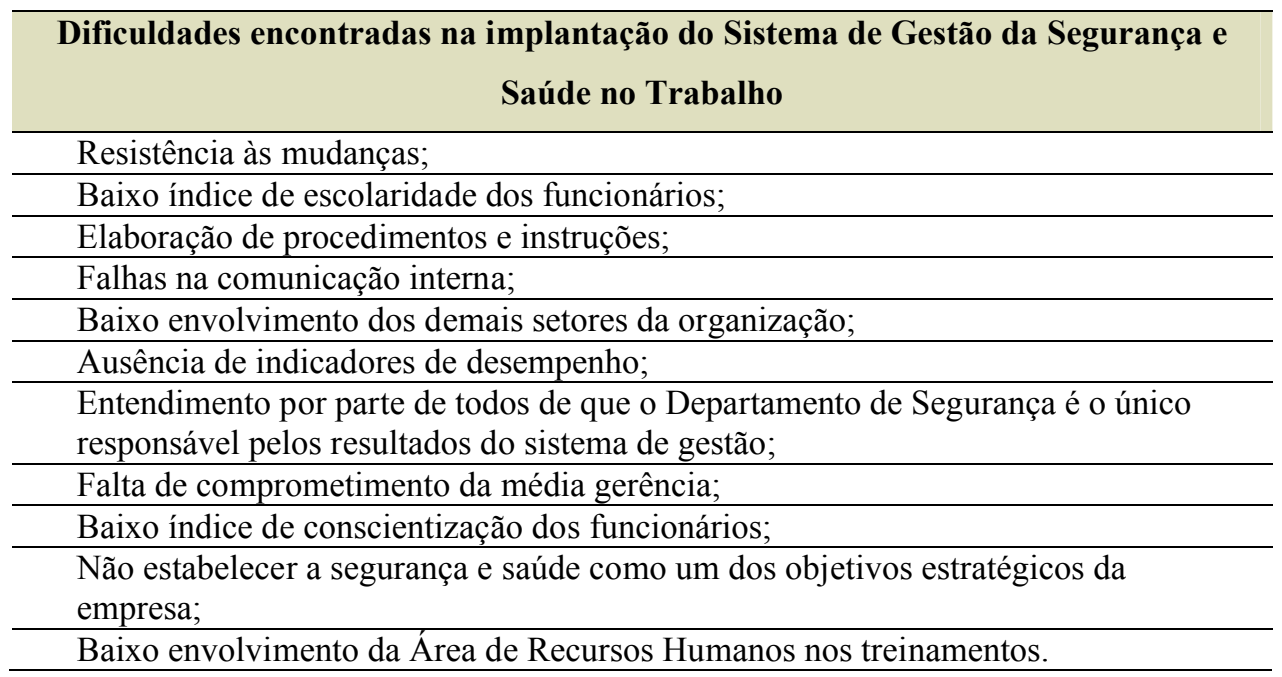

O baixo envolvimento da Área de Recursos Humanos nos treinamentos realizados pela organização é visto como um obstáculo para a conscientização dos envolvidos no processo de implantação do Sistema de Gestão da Segurança e Saúde no Trabalho. A participação do setor é muito tímida, sendo que os maiores esforços ainda se concentram nas mãos dos técnicos de segurança no trabalho da empresa.

A organização investe pouco em ferramentas de comunicação interna, como painéis, banners entre outros, de forma que muitos funcionários desconhecem os novos programas desenvolvidos pela empresa, ocasionando, desta maneira, baixo índice de envolvimento e resistência às mudanças propostas.

\section{Diretrizes gerais para a implantação de Sistemas de Gestão da Segurança e Saúde no Trabalho em empresas industriais}

Este estudo tem como base um referencial teórico, que foi sinteticamente apresentado neste artigo, e um estudo-de-caso realizado em uma empresa fabricante de baterias automotivas, com função exploratória, objetivando ratificar a teoria estudada e possibilitar a formulação genérica e introdutória de algumas diretrizes para minimizar as dificuldades na implantação de sistemas de gestão da segurança e saúde em empresas industriais. São elas: 


\subsection{Comprometimento da Alta Direção}

O sucesso na implantação de sistemas de gestão da segurança e saúde no trabalho depende da habilidade dos agentes responsáveis pelas mudanças em controlar situações complexas e imprevisíveis

A aceitação e o entendimento do conceito da segurança e saúde por parte da Diretoria e o seu comprometimento é de fundamental importância. São os superiores hierárquicos que devem dar o exemplo por meio de suas próprias ações e a constante busca de adesões a este processo.

Desta maneira, quando começam a acreditar no real comprometimento da Direção para com o sistema, os funcionários se tornam mais dispostos a cooperar com as melhorias de desempenho na segurança e saúde na organização.

O comprometimento da Alta Direção foi evidenciado no estudo-de-caso realizado, por meio da constatação de vários investimentos realizados na adequação do ambiente às condições seguras de trabalho, bem como na participação ativa da Alta Direção nos projetos relacionados à segurança dos trabalhadores.

Com estas ações, observa-se que a maioria dos funcionários da organização se sentem mais dispostos em participar do processo por meio de ações, como sugestões para a melhoria do ambiente de trabalho e auxílio na conscientização dos demais trabalhadores.

Cabe também salientar, que a iniciativa de se implantar um sistema de gestão da segurança e saúde no trabalho partiu dos Diretores da empresa.

\subsection{Minimização das resistências às mudanças}

Mudanças sempre acarretam reações de medo e insegurança por parte daqueles que estão envolvidos com ela, e a sua eficácia está fortemente dependente do seu planejamento, da habilidade das lideranças em estabelecer objetivos e metas e do entendimento por parte dos envolvidos dos objetivos da organização. As pessoas podem ser menos resistentes às mudanças a partir do momento que começarem a entender a sua verdadeira natureza e sua importância para a organização e para suas próprias vidas.

Fenômenos como conflitos, incertezas, medo do desconhecido, falta de informação e sensações de perda de poder podem gerar resistências às mudanças propostas e interferir negativamente na implantação de sistemas de gestão da segurança e saúde no trabalho nas organizações. Estas resistências podem ser minimizadas por meio de ações de incentivos à participação no processo e a valorização de opiniões, à capacitação e a adequada disponibilização de informações. 
$\mathrm{Na}$ empresa estudada foi verificado que a resistência às mudanças, na maioria das vezes, tem início na média gerência; e isto está vinculado ao medo que estes profissionais, com vários anos de empresa, têm de vivenciar situações desconhecidas e não conseguir adaptar-se a elas.

A organização procura minimizar estas resistências, por meio de treinamentos de conscientização sobre o assunto e comunicação interna dos benefícios que um sistema de gestão pode proporcionar.

\subsection{Identificar aspectos da cultura da organização que podem contribuir ou prejudicar a implantação de Sistemas de Gestão da Segurança e Saúde no Trabalho}

Fazer uma análise prévia do perfil dos colaboradores, identificando o grau de escolaridade, o seu comportamento na execução das atividades, bem como o relacionamento com as lideranças e demais funcionários. Estes são fatores importantes para que se consiga antecipadamente identificar as principais resistências que podem surgir durante um processo de implantação de sistemas de gestão, tentando saná-las previamente de maneira a não causar perturbações desnecessárias ao processo.

\subsection{Capacitação técnica e gerencial do profissional responsável pela gestão da segurança e saúde no trabalho na empresa}

O perfil do profissional responsável pela gestão da segurança e saúde no trabalho é importante para que se consiga a adesão de todos os colaboradores em programas de gestão da segurança e saúde no trabalho. Além do conhecimento técnico, é necessário que ele tenha habilidades como comunicação e relacionamento interpessoal.

Na empresa estudada, os técnicos de segurança e saúde no trabalho possuem habilidades técnicas e gerenciais, e têm consciência de que, para trabalhar em equipe e gerenciar pessoas, é necessário buscar uma forma de mostrar os benefícios individuais e coletivos de se buscar a prevenção de acidentes. Com este trabalho, a cultura de segurança vem sendo disseminada na organização, fazendo com que os funcionários se sintam responsáveis pela segurança no ambiente de trabalho.

A habilidade em comunicação não envolve somente a capacidade de disseminar a informação em forma verbal ou escrita, mas ser capaz de transformá-la em uma linguagem compreensível para todos os trabalhadores. 


\subsection{Não havendo experiência no assunto, avaliar a necessidade de se contratar uma consultoria}

Algumas organizações, principalmente pequenas empresas, podem ter necessidade de contratar uma consultoria para auxiliar seu quadro pessoal na implantação ou melhoria de seu sistema de gestão da segurança e saúde no trabalho.

Este fato se deve tanto a falta de experiência prática do profissional da segurança e saúde no trabalho e demais líderes da empresa, como a necessidade de se buscar a utilização de novos conceitos e ferramentas nesta área de gestão.

$\mathrm{Na}$ contratação de uma consultoria, o contato com organizações por ela já auxiliadas é uma medida importante sua avaliação, pois por meio destas informações é possível avaliar sua experiência, eficácia, bem como seu comportamento ético durante os serviços prestados.

\subsection{Investir fortemente em comunicação interna com o objetivo de esclarecer os empregados sobre os novos procedimentos ou novo sistema de gestão da segurança}

A empresa deve utilizar meios e técnicas de comunicação compatíveis com o nível de cultura de seus funcionários, a fim de informar a todos sobre os objetivos da empresa e as oportunidades que novos procedimentos ou um novo sistema de gestão estruturado da segurança pode proporcionar.

Realizando isto de maneira eficaz, pode ser estabelecido um alto nível de entendimento e cumplicidade entre a empresa e seu quadro de funcionários, eliminando boatos capazes de gerar temores e transtornos contraproducentes.

$\mathrm{Na}$ organização onde o estudo-de-caso foi realizado, o investimento em comunicação interna ainda é pequeno, o que causa desconhecimento por parte de muitos funcionários sobre novos programas relacionados a segurança e saúde no trabalho.

\subsection{Investir em treinamentos técnicos e comportamentais para formar mão-de-obra capacitada e consciente}

O treinamento deve ser entendido como um meio estratégico de desenvolver competências para que os funcionários se tornem mais produtivos, criativos, inovadores e possam contribuir para o alcance dos objetivos organizacionais. Para isto, é necessário que sejam planejados de acordo com as necessidades identificadas e de acordo com os requisitos exigidos em cada função. 
As necessidades de treinamento podem ser identificadas por meio de ferramentas de avaliação das competências exigidas. No caso de implantação e gerenciamento de um sistema de gestão da segurança e saúde, o treinamento ganha uma dimensão ainda maior, pois é a partir dele que se dá a grande oportunidade de mobilização da mão-de-obra para a questão da segurança.

$\mathrm{Na}$ empresa estudada, estes treinamentos têm como objetivos informar e estimular a utilização da inteligência, da criatividade, da comunicação e da autonomia das pessoas como recursos para o desenvolvimento das organizações. As pessoas precisam ser treinadas e motivadas da maneira mais adequada possível, criando um alto grau de conscientização quanto aos benefícios das normas de segurança e saúde para empresa.

Com os treinamentos já realizados alguns resultados podem ser notados, como o maior envolvimento e comprometimento destes trabalhadores, principalmente do chão de fábrica e redução do índice de acidentes.

\subsection{Trabalhar em estreita parceria com a área de recursos humanos}

A integração entre departamentos gera resultados positivos para toda a organização e possibilita a construção de um ambiente interno com menos conflitos e resistências.

O envolvimento da área de recursos humanos em todos os processos de mudança é importante para que sejam identificadas as necessidades de treinamento relacionadas ao desenvolvimento dos funcionários, bem como a utilização de técnicas apropriadas para realização deste trabalho; possibilitando um melhor entendimento e um real comprometimento dos colaboradores com as mudanças propostas.

No estudo-de-caso realizado constatou-se que ainda é pequena a participação da Área de Recursos Humanos no processo de implantação do sistema de gestão da segurança e saúde no trabalho. Porém, pequenas ações estão sendo feitas em conjunto com a área de segurança no trabalho, e bons resultados já podem ser verificados, como maior entendimento e participação dos trabalhadores envolvidos em programas de segurança no trabalho.

O sistema deverá ser avaliado de acordo com os requisitos do sistema de gestão da segurança e saúde no trabalho implantado na empresa. Todos os funcionários da organização devem ser avaliados por meio de entrevistas e pesquisas de clima organizacional.

\subsection{Definir indicadores de desempenho em segurança no trabalho e retro-alimentar o sistema}

Definir, juntamente com as demais áreas da organização, indicadores de desempenho em segurança e saúde, bem como outros que identifiquem oportunidades de melhorias e verifiquem a 
evolução do sistema, tais como, indicador do índice de acidentes com ou sem afastamento (acidentes/ horas trabalhadas), números de acidentes fatais, entre outros.

Eles têm como objetivo permitir que a Alta Direção e os demais colaboradores visualizem o desempenho do sistema de segurança e saúde da empresa, permitindo, a partir disto, a realização de uma auto-avaliação da performance e o estabelecimento de planos de ação para eventuais correções dos objetivos e metas estabelecidos.

No estudo-de-caso realizado, a empresa tem definido seus indicadores de desempenho em segurança e saúde no trabalho, e todos os acidentes e incidentes são comunicados a todos os funcionários, os quais participam do planejamento e execução das ações corretivas e/ou preventivas.

\section{Conclusão}

Ao longo dos últimos anos, as organizações têm alcançado inúmeros benefícios com a implementação de sistemas de gestão. Porém, muitas vezes, neste processo surgem dificuldades que podem reduzir seus potenciais resultados.

Este trabalho possibilitou a formulação de algumas diretrizes gerais e introdutórias, apresentadas aqui de forma resumida, com objetivo de minimizar as dificuldades na implantação de Sistemas de Gestão da Segurança e Saúde no Trabalho.

Estas diretrizes foram elaboradas a partir de uma revisão teórica. Contudo, um estudo-decaso exploratório foi realizado em uma empresa fabricante de baterias automotivas com o objetivo de adensar os preceitos teóricos e auxiliar refinar a elaboração das diretrizes.

O referencial teórico, apresentado neste artigo de forma condensada em função da limitação de espaço, nos permitiu verificar as principais dificuldades encontradas pelas organizações na implantação de sistemas de gestão da segurança e saúde no trabalho, bem como sugestões para minimizá-las, tendo sido isto fundamental para realização do estudo-de-caso.

No estudo-de-caso apresentado foi possível analisar um sistema de gestão da segurança e saúde e evidenciar as principais dificuldades encontradas em sua implantação. Na análise dos fatos levantados ficou claro que o apoio da Alta Direção, da área de Recursos Humanos e a participação de todos os colaboradores é determinante para o sucesso ou fracasso do referido sistema de gestão, corroborando com o que a teoria já preceituava.

As dificuldades apresentadas estão vinculadas a diversos fatores, mas podemos destacar como os mais importantes à falha na comunicação entre os níveis superiores de gerência e o chão de fábrica ou nível operacional, o baixo grau de participação dos trabalhadores, o inadequado planejamento das ações a serem tomadas, a insegurança dos funcionários, a ausência de indicadores para a medição de desempenho, entre outros. 
Os reais benefícios que a implantação de um sistema de gestão da segurança pode propiciar aos funcionários e a própria empresa, em geral, não são devidamente esclarecidos. Dessa forma, fica muito mais difícil à motivação e o comprometimento do colaborador com a causa da segurança, acarretamento, desta forma, incertezas e medo em relação a este tipo de mudança.

Os estudos realizados permitiram verificar e concluir que são várias as dificuldades encontradas na implantação de sistemas de gestão, sendo que elas poderiam ser minimizadas por meio de um planejamento estratégico e financeiro adequado, investimentos em treinamentos, contratação de profissionais capacitados e comprometimento dos funcionários com relação ao sistema de segurança e saúde da empresa. Acreditamos que o objetivo deste trabalho foi alcançado, pois por meio do estudo-de-caso conseguimos confirmar informações da teoria e formular diretrizes, ainda que genéricas e introdutórias, para a implantação de sistemas de gestão da segurança e saúde no trabalho.

O estudo-de-caso realizado foi fundamental na formulação das diretrizes, pois possibilitou verificar o envolvimento da Alta Direção para com o sistema de gestão da segurança e saúde no trabalho, os obstáculos encontrados pelos profissionais da área de segurança na conscientização dos trabalhadores de chão de fábrica e média gerência, a conscientização de que o envolvimento da área de recursos humanos é importante para o sucesso do programa, a necessidade de realização de constantes treinamentos de conscientização, bem como a importância de se buscar dentro da empresa um sistema de comunicação interna adequado, que possibilite o entendimento e o envolvimento de todos os funcionários em busca de objetivos comuns.

Como limitações, podemos verificar que o trabalho foi desenvolvido em uma empresa industrial localizada na região de Bauru, cabendo também salientar que as diretrizes propostas ainda não foram testadas e a maioria delas está baseada na teoria apresentada. Uma pesquisa quantitativa tipo survey está em andamento, e tem como objetivo ampliar e dar maior embasamento às diretrizes propostas.

\begin{abstract}
Currently organizations face daily challenges about their profitability, quality, technology and sustainable development. In this context, the Safety and Health Management Systems acquire a more and more meaningful role regarding the performance of the organization since it reduces the risk of accidents; promotes health and workers' satisfaction and improves the image of the organization towards the community. However, for an occupational health and safety management system to be effectively implemented and obtain good results, companies need to be aware of the difficulties encountered during this process, and try to solve them in an effective and coherent manner with their objectives. As mentioned, the main objective of this paper, which is based on the theoretical referential, is to identify the main difficulties and propose guidelines for implementing Occupational Health and Safety Management Systems. A case study with an exploratory function was also performed at a Brazilian automotive battery manufacturer.
\end{abstract}


Key-words: management systems; occupational health and safety; OHSAS 18001.

\section{Referências}

ANHALON, R.; ZOQUI, E. J.; PINTO, J. S. Principais dificuldades vivenciadas na implementação de um sistema de gestão da qualidade adaptado em empresas incubadas na região de Jundiai. In: ENCONTRO NACIONAL DE ENGENHARIA DE PRODUÇÃO, 25, 2005, Porto Alegre. Anais... Porto Alegre: ABREPO, 2005. 1CD-ROM.

BARBOSA FILHO, A.N. Segurança do trabalho \& gestão ambiental. São Paulo: Atlas, 2002.

BEER, M.; NOHRIA, N. Desvendando o código da mudança. Revista HSM Management, n. 25, p.126-132, 2001.

BRITISH SANTANDARD INSTITUTIONS. BS 8800: Guide to occupational health and safety management systems. London, 1996.

BRITISH SANTANDARD INSTITUTIONS . OHSAS 18001 - Occupational health and safety management systems: requirements. London, 2007.

BROWN, K. A. Workplace safety: A call for research. Journal of Operations Management, vol. 14, issue 2, p. 157 $171,1996$.

cross ref

CAGNIN, C.H. Fatores relevantes na implementação de um sistema de gestão ambiental com base na Norma ISO 14001. Santa Catarina: UFSC, 2000 (Dissertação de Mestrado em Engenharia de Produção).

CHOUDHRY, R.M. et al. The nature of safety culture: A survey of the state-of-the-art, Safety Science, vol. 45, issue 10, p. 993-1012, 2006.

HASLE, P.; JENSEN, P. L. Changing the internal health and safety organization through organizational learning and change management. Human Factors ans Ergonomics in Manufacturing, vol. 16, issue 3, p. 269-284, 2006.

LAKATOS, E.M.; MARCONI, M.A. Técnicas de Pesquisa. 5 ed. São Paulo: Atlas, 2002.

MILAN, G. et al. A relação entre a gestão da qualidade e a cultura organizacional: um estudo de caso ambientado em uma fábrica de embalagens de papelão. In.: ENCONTRO NACIONAL DE ENGENHARIA DE PRODUÇÃO, 25, 2005, Porto Alegre. Anais... Porto Alegre: ABREPO, 2005. 1CD-ROM.

QUELHAS, O. L. G.; ALVES, M. S.; FILARDO, P. S. As práticas da gestão da segurança em obras de pequeno porte: integração com os conceitos de sustentabilidade. Revista Produção On Line. vol. 4, n. 2 , 2007. Disponível em $<$ www.producaoonline.inf.br>. Acesso em 01 abr. 2007.

SILVA, S. et al. OSCI: an organizational and safety climate inventory. Safety Science, vol. 42, issue 3, p. 205-220, 2004.

cross ref

TRIVELATO, G. C. Sistema de gestão da segurança e saúde no trabalho: fundamentos e alternativas. Apresentação feita no Seminário Nacional sobre gestão da segurança e saúde no trabalho. FUNDACENTRO, Belo Horizonte, MG, $2002 . \quad$ Disponível

$<$ http://www.fundacentro.gov.br/CTN/sistemas_gestao_saude_trabalho.pdf $>$. Acesso em 01 abr. 2008.

YIN, R.K. Case Study Research: design and methods. 3 ed. Sage Publications, 2003. 
Nome completo: Alessandra Bizan de Oliveira

Filiação institucional: UNESP - Bauru

Departamento: Engenharia de Produção

Função ou cargo ocupado: Mestranda

Endereço completo para correspondência (bairro, cidade, estado, país e CEP): Av. Luiz Edmundo

Carrijo Coube, 14-01. Vargem Limpa - Bauru - SP. Cep 17033-360

Telefones para contato: (14) 31036122

e-mail:alebizan@terra.com.br

Nome completo: Otávio José de Oliveira

Filiação institucional: UNESP - Bauru

Departamento: Engenharia de Produção

Função ou cargo ocupado: Professor Doutor

Endereço completo para correspondência (bairro, cidade, estado, país e CEP): Av. Luiz Edmundo

Carrijo Coube, 14-01. Vargem Limpa - Bauru - SP. Cep 17033-360

Telefones para contato: (14) 31036122

e-mail:otavio@feb.unesp.br 